I Pontifícia Universidade Católica do Rio de Janeiro (PUC-Rio),

Programa Nacional de Pós-doutorado/Capes, Rio de Janeiro, RJ, Brasil

carolbalt@gmail.com

https://orcid.org/oooo-0003-3462-3356

I I Universidade Federal do Rio de Janeiro (UFRJ), Programa de

Pós-Graduação Eicos - IP e Escola de Comunicação, Capes/Print,

Rio de Janeiro, RJ, Brasil

Ana Carolina Balthazar '

monica.machado@eco.ufrj.br

https://orcid.org/oooo-0002-2558-5426

\title{
MATERIAL CULTURE AND MASS CONSUMPTION: THE IMPACT OF DANIEL MILLER'S WORK IN BRAZIL
}

This special issue reflects on the impact of the work of the English anthropologist Daniel Miller, trained in archaeology and anthropology at Cambridge University in the United Kingdom, on diverse research fields of the social sciences in Brazil. In this introduction we present an interpretation of the arguments set out in the book Material culture and mass consumption, first published in I987, a fundamental work for comprehending the theoretical framework proposed by Miller, never translated into Portuguese. Additionally, we also offer a critical reflection on the continuing relevance of this theory about consumption for debates in the social sciences today. We also present an interview with Miller in which we were able to discuss some of our impressions concerning his career and writings. In the articles that follow in this special issue, different authors were invited to discuss the relevance of Miller's work for their own theoretical production. Finally, in the section Research Records, Brazilian researchers who worked directly with Miller provide a brief account of their experience.

\section{A REVIEW OF THE BOOK MATERIAL CULTURE AND MASS CONSUMPTION}

In the book, Miller undertakes a review of the concept of objectification, initially formulated by G. W. Hegel (I977). According to Miller, the concept refers to the way in which subjects and objects are mutually constituted. It is only when subjects externalize aspects of themselves in objects - that is, when they differentiate themselves into an "other" - that they become aware of their own 
being. Next, since the externalized object itself possesses aspects of the subject, the latter reidentifies with the object, seeing themselves in the object like a mirror. It is in this play of differentiation and identification that subject and object are reciprocally constituted. In this sense, the existence of a subject depends on the process of continual externalization and reincorporation of the object. "Object" here is used in the conceptual sense as any other body not part of the subject. Thus, people at some level depend on the materialities externalized in the world to constitute themselves as persons.

In his work, Miller also considers the centrality of the historical axis for Hegelian theory. Over the historical process, the dynamics of externalization and identification are seen to advance progressively until attaining an absolute knowledge of existence. According to Miller, it is important we consider the way in which the externalization of the subject in an object and its sublimation is constitutive of the subject, not just representative. It is in the act of forging the object that the subject constructs her or himself. This is how Miller traces his own understanding of the concept of culture. Culture is, for him, the outcome of this continuous historical process of the dialectical relation between subjects and objects.

It is on these grounds that Miller proceeds to interpret the arguments of Karl Marx (I975) concerning the impact of capitalist industrial production on the subject's alienation. The process of industrial production forces the subject to externalize objects at an accelerated pace. As each subject performs a minimal function in this large-scale production of objects, the final item possesses very little of the subject who helped to create it. According to Marx, the subject becomes alienated, therefore, distanced and abstracted from her or his own work, and the process of self-realization is rendered impossible. Inspired by Georg Simmel (I978), Miller argues, however, that by nature there exists a contradictory condition in the subject/object relation beyond the industrial dynamic. The subject needs to externalize part of her or himself to give rise to the object: in other words, the distancing between subject and object is fundamental. In this sense, the problem of the industrial system is not alienation per se, but the way in which at certain times the social dynamic has made it impossible for the materialized object to be subsequently reincorporated by the subject. In this sense, Marx's theory did not contemplate the centrality of consumer relations for the Hegelian process of objectification, consumption allowing for the re-incorporation of the alienated object. Miller argues for the relevance of analysing consumer practices to comprehend the contemporary subject - and the construction of her or his subjectivity.

Given the centrality of objects for the constitution of the subject, Miller goes on to advocate the importance of research methods that not only include social relations, but also focus on the role performed by objects themselves in this process. The author turns to theses of child development to reinforce his 
argument about the centrality of objects in the constitution of subjects. Citing Jean Piaget (I962) and Melanie Klein (I975), Miller contends that objects, prior even to words, perform a fundamental role in the process of infant cognitive development. In other words, in parallel to anthropological theories that elaborate a notion of culture as networks of meanings that give sense to the world, Miller pays attention to the role performed by materiality in the development of a symbolic process - thereby configuring the field of studies known as "material culture."

Thus, a research methodology elaborated by social scientists interested in the material dimension of culture should perceive objects as "cues" (Goffman, I975) or "frames" (Gombrich, I979). For Miller (I987: I02), it is essential to realize that "unconscious, non-linguistic processes may act to control conscious and linguistic articulation. This is not to deny some level of autonomy to the latter, but to reject assertations of its virtual total autonomy." In other words, as a frame that silently directs our gaze, objects also humbly direct our consciousness. Here Miller underlines the importance of Pierre Bourdieu's contribution (I977) to our understanding of the relevance of objects in processes of power negotiation. Studies of material culture should, therefore, observe and analyse the symbolic properties presented by objects. This aim, in turn, requires accompanying consumer practices given that in industrialized societies consumption is central to Hegelian processes of objectification.

Finally, in the book the author argues that the social sciences have given an extreme emphasis to production processes in detriment to the practices of consumption. In this sense, there is no historical primacy of production practices in relation to consumption practices, but rather a difference in analytic focus. It is through paying attention to consumption that Miller discusses, for instance, works like that of Dick Hebdige (I98I) on how scooters were "appropriated" by English consumers in the Ig6os and attributed meanings and functions not initially foreseen by the industry. Put otherwise, the subjects used these objects of consumption to negotiate and react to the social frameworks imposed on them. Miller stresses that it is crucial to accompany this process through which goods are appropriated, since only in this way can the researcher comprehend exactly how the individual is giving new meanings and using or transforming these consumer goods.

Thereafter, Miller will develop diverse studies that focus on consumers. Among the books published in Portuguese, we can cite a few examples. In Teoria das compras (Miller, 2002) - A theory of shopping - the anthropologist accompanies residents from North London on their trips to the supermarket. He shows, for instance, not only how the purchase of items "marks" and "stabilizes" (Douglas \& Isherwood, I979) existing social relations, but also how the very negotiation of the objects constitutes relations: between parents and children, spouses or friends. In turn, in the book Trecos, troços e coisas (Miller, 20I3) - Stuff 
(Miller, 20I0) - we can observe how in diverse societies analysed by Miller, for example in India or Trinidad, people are invested in different processes of appropriating objects.

Miller's proposed research methodology is fundamental to comprehending his critique of diverse theorists of the "culture industry" (Adorno \& Horkheimer, I944). Echoing Bourdieu's critical reading of the role of the academic system in the reproduction of social hierarchies, Miller argues that many moralist theses concerning consumer society act as an instrument of class distinction, seeking to reinforce the intellectual power of some through the stigmatization of others. Throughout his career, Miller has remained a strong critic of theories that contribute to "elitist" knowledge (something the author himself explains in the interview contained later in this special issue).

In response to Miller's propositions, at least two critiques may emerge. On one hand, the term "material culture" could reinforce the very same dualism that diverse currents of anthropology have tried to surpass. Apropos this argument, Miller has explained that the choice of the term arose from its capacity to communicate the proposed theoretical discussion to a broader audience (Miller, 2005: 4). In other words, the choice of the term "material culture" prioritizes a dialogue with these people who are not necessarily immersed in the complexity of the conceptual debate in academia. It should serve, therefore, to remind people in general about the overlapping of more ideological and physical dimensions. Perhaps the relevance of the conceptual strategy proposed by Miller is shown by its considerable impact on an international interdisciplinary debate (see Miller, I995a). By prioritizing a term that sacrifices some "purisms" of the anthropological debate, Miller can engage in a debate with geography, history, sociology, media studies and other areas (as we shall also see in the articles contained in this special issue).

On the other hand, a critical evaluation of the arguments proposed by Miller might argue that individuals have only a limited power to act as consumers in the face of the structural force of an economic system of mass production. In other words, although individuals may be "appropriating" and giving new meanings to the products offered by the market, their capacity to act is still limited by the interests of the market itself. In response to this assertion, the author argues that the scenario is a little more complex than pure domination, and needs to be investigated ethnographically, given that the consumer increasingly influences the production through the market surveys developed by the industry (Miller, I995b: 4).

Today, looking back at Miller's work, perhaps we can consider it embryonic of a project that would emerge later with the "ethical turn" of anthropology in the I990s (Balthazar, 202I). Led by authors like James Laidlaw (2013), the ethical turn in anthropology seeks to extricate itself from some of the theoretical vices inherited from the conceptual framework proposed by Durkheim. In his 
conceptualization, Durkheim opposes society and individual, the latter destined to respect or revolutionize the ethical and moral norms established by the former. Inspired by Foucault, Laidlaw argues for the importance of theoretical perspectives that recognize the individual's reflexive capacity to evaluate and act on her or his life. The "ethical turn," therefore, proposes that anthropological studies avoid attempting to map large ethical paradigms to focus instead on the everyday practices in which subjects attempt to construct themselves as ethical beings (Mattingly \& Throop, 20I8). In the I980s, Miller already appeared to announce the importance of the analytic focus on individual processes of constructing the subject. Thus, it is the concentration on the routine and particular appropriations developed by social subjects that reinforce the importance of ethnography in Miller's work. Miller (2017a) positions himself as a strong advocate of ethnography and "critical empiricism". In other words, the long-term immersion in the social practices under study becomes essential for the analyst to perceive how other people resignify and transform theoretical premises.

It is worth noting that this methodological strategy not only confers the possibility for greater creative autonomy for the subject under analysis, but also offers opportunities for the researcher too. If the empirical data possesses such relevance for the production of theory, any junior researcher who develops careful ethnographic research is already qualified for a debate with the field's major thinkers. It can even be suggested that Miller's methodological approach has consequences for anthropological practice given that it anticipates the destabilization of conceptual structures (and disciplinary canons) through a prioritization of empirical data. In this way, it provides a more welcoming space for the experience of new researchers. The author's way of doing anthropology reproduces the same values that he advocates at the theoretical level concerning the democratization of knowledge.

\section{A NEW OBJECT: MEDIATIONS, HUMANITIES AND TECHNOLOGIES}

Two of Miller's recent projects are key references for comprehending his anthropological perspective of humanity and consequences of uses of media cultures. Both projects are developed by the Material Culture section of the Anthropology Department of University College London under Miller's supervision: Why We Post and ASSA (Anthropology of Smartphones and Smart Ageing). ${ }^{.}$The latter is an ongoing five-year project investigating from an anthropological perspective the mediations of smartphones in contexts of promoting health for the public over the age of 45 . Miller and his research group offer us thoughtprovoking reflections on anthropology's contributions to the analysis of the sociocultural mediations between social subjects, digital media learning processes, and relations between technologies and humanities.

In the book Digital anthropology, Horst and Miller (20I2) propose six basic principles for comprehending the field. In so doing, they present the key ques- 
tions for analysing the digital as a subdiscipline of anthropology. The first notion derives from the view that the digital intensifies the dialectics of contemporary cultural life. The digital is seen as a privileged cultural space since it produces a proliferation of particularities and differences, depending on the context where its social uses emerge. Interested, therefore, in human social relations and in the ways of interacting in everyday life, anthropologists investigate the ethnographic experiences of particular social groups in local contexts and that invest in discovering the reasons for use of the technologies and their potential for valorising local singularities or possible universalizations.

The second principle suggests that social subjects are neither more nor less mediated following the growth of the digital era. Dialoguing with Goffman (I975), Horst and Miller (20I2) turn to the concept of "frame" to think about the processes of framing mediations, whether in face-to-face relations or in the complex contemporary relations mediated by technologies. All modes of interaction involve complex mediative dimensions, as in face-to-face exchanges - interjections, non-verbal communications, gazes, bodily codes - and in the digital phase through the mediation of smartphones. Online arenas are perceived as spaces just as effective for interaction as physical spaces. And precisely for this reason digital cultures interest the anthropological tradition, as culturally relevant spaces for observing the cultural practices of lives lived by social subjects. In the study of the kinship relations of Filipina mothers who live in London and their children who stayed in their homeland, Madianou and Milller (2012) formulate the concept of mediated motherhood, arguing that it is possible to identify very rich variations in the modes of social interactions of the affects mediated by technology.

Another principle is to define the digital through dialectics. Setting out from the premise that the digital derives from binary culture, we can observe the possibility of its historical precedents. For Horst and Miller (201 2), the same system of the contemporary digital environment founds the modern financial system. Globally, money represented a new phase of human abstraction that simultaneously reduced and commoditized social relations while expanding them in terms of difference and plurality. The principle of dialectics should, therefore, comprehend the fact that the uses of digital technologies can contradictorily expand both movements. The authors call on anthropologists to focus attention on this spectrum and allow the ethnographic experience to lead them to the analysis of the social uses of technology. In the book The internet: an ethnographic approach, Miller and Slater (2000) had already signalled ethnography's fundamental contribution to studies of the internet and to investigating how the digital field is assimilated in local contexts. More than study the uses and effects of the media, the anthropological experience focuses on how members of a specific culture act in their communicative actions and how they try to attribute singular meanings to their own social universes. 
Returning to the principles of digital anthropology, the notions of voice and dialogue between relativism and holism are fundamental concepts. Horst and Miller (2012) point out that cultural relativism is part of the backbone of anthropology. While the notion that the digital environment standardizes social relations forms part of the contemporary imagination, ethnographic studies of the uses of digital media on different platforms combine regional and parochial factors with possible levels of generalizations. Here in Brazil, for example, my ethnographic study of the uses of social media in the Favela Museum in Cantagalo, Pavão and Pavãozinho in Rio de Janeiro revealed very rich dimensions of the modes of interaction of young people from the community and their modes of engagement with the museum's platforms (Machado, 20I7) gravitating around themes as expressions of citizenship, identity contexts, regimes of visibility/invisibility in public space. Meanwhile the study of Spyer (20I7) with a local community in Bahia revealed other dimensions of socialities, some related to local conditions, experiences of digital learning, socioaffective exchanges, social aspirations and accounts of the everyday life of residents.

The debate on the ambivalence of the opening and closure of worldviews is the next principle. The internet very often promises to open up spaces for activists and political mobilization outside the traditional field of the large media corporations. At the same time, new forms of controlling and limiting the freedom of expression have also appeared. The work of Sonia Livingstone (2002) on the opportunities and risks involving the digital world is a good example of the opening and closing of worldviews. Much has been discussed about the potential openness of the internet for young people in terms of stimulating learning, developing relationships in non-geographic territories, exchanges and rich cultural interchanges, but, conversely, also the freer access to dangerous content like pornography, violent videos or paedophilia.

Another important concept in Miller's work is the "theory of attainment," a notion developed in the book Webcam by Miller and Sinanan (2014). To explain the concept, the authors revive the discussion on authenticity as one of the primary discursive keys for understanding the anthropological vision of the cultural uses of technology. They argue that it is commonly held that the emergence of digital cultures provoked the decline of preceding sociocultural experiences. They recall, though, that a similar critique was made by Plato in discussing how writing, as a support beyond the mind, could be seen as an expressive device that values memory and the cognitive dimensions less. The starting point, therefore, is that the digital world is part of the lived lives of subjects, meaning that they are just as interesting for anthropological analysis and just as cultural as other forms of mediation. The authors observe, then, that if we are neither more nor less mediatized by digital culture, what has changed in contemporary cultural experiences in relation to previous cultural modes? The idea underlying this view is that older cultural experiences leave their marks on the new modes 
of mediation and thus become important to comprehending what is retained of previously active sociocultural modes and to identifying new sensibilities distilled by the relations with new media. When we talk about webcams, the paradox lies in the fact that there are dimensions of humanity that are new and others that are activated from previous cultural connections (moral, social, political, relational) that can be either potentialized or reduced in digital life. The expression of self-consciousness, for example, is one of the modes of mediation cited by the authors. In social uses of the webcam we can see, as well as others, ourselves mirrored in a contemporary fashion. This is a new phenomenon in our culture and implies debates on the impacts on subjectivities, a strange disconcertedness in the gaze and in the self-image. Another mark of "attainment" can be seen as the place of intimacy in the relations via webcam. The sense of copresence between people living in physically separate locations signals new meanings of sociabilities, revising the place of the home and intimate space. What is interesting to observe is that digital experiences can be different and more diachronic than synchronic in relation to different cultures.

In 2012 in the book Migration and new media: transnational families and polymedia, Madianou and Miller (20I2) analyse the concept of polymedia - that is, sociocultural mediations and consumption in digital contexts. Mapping the analytical categories proposed to investigate the social uses of technology - such as access to infrastructure, cost analysis, user friendliness and skill - the authors promote a debate on the digital field referring to the narrative dimensions of sociality (collective experiences of using technologies among the reference groups), the dimensions of power relations, which are strongly associated with asymmetries and questions of literacy - knowing the language, the capacity to produce content - and with emotional attributes - affective bonds with digital devices and their logics. The focus of this theory is not to investigate digital platforms but the modes of mediation of users and their preferences for digital languages, practices and processes.

The concept of "polymedia" also presumes the analysis of narratives that interfere in the choices on how digital media are used. One of these fields is the dimension of sociality. Madianou and Miller (20I2) assert that diverse motivations intervene in the choices of which communication devices to use for digital interaction. In many circumstances, these choices are motivated by relationships, people to stimulated to share the same cultural spaces as their peers. With this spirit of investigation, Miller entered the world of the hospices in an English village in one of his most recent works.

\section{THE COMFORT OF PEOPLE: LIFE, EXPECTING DEATH AND MEDIATIONS}

In his book The comfort of people Miller (20I $\mathrm{b}$ ) describes his ethnographic experiences in a hospice (a place where terminal patients are treated) in an English village. Based on the narratives of the subjects and their experiences with 
social media, the book is a moving account of life and its meanings in a context of imminent death. The concept of hospice is relevant since it is not a hospital for long-term admissions: the patients prefer to live at home and go to the centre for holistic health treatments and meetings with the local community. Precisely because of the specificity of this mode of treatment, the patient communication system - with medical staff, carers and relatives - is extremely important. It is interesting to observe that the project combines classical anthropological investigation with applied research, since at the end of the study Miller includes a technical report with guidelines for doctors, carers and healthcare professionals on best practices for the use of smartphones in the context of patients.

The book's title is a reference to the author's previous work, The comfort of things, published in 2008. In the latter ethnographic study, Miller investigated a street in London given the fictitious name of Stuart Street, where he presents the ways of life of 30 residents who describe themselves and their life histories through objects in the home. Thus, the life portraits of the participants are described through the activation of memories related to these objects, flowing into the debate on the interweaving of material culture and people. Thus, the work involves an enriching view of the lives of certain "Londoners" in the contemporary multicultural context.

In The comfort of people, the dynamic is similar: the depictions of the patients also involve fictitious names, but the work essentially examines social expressions in the context of the relations between patients and the community, friends, and family, the feelings of isolation, solitude, connection, and co-presence. The narratives detail their life experiences, describing places, people and perceptions of moments of joy, sadness, depression, life and death, the legacy of the past, and the future.

The concept of "polymedia" is explored again in this work to comprehend, above all, the ecosystem of connections to which patients turn to communicate with carers, relatives and doctors. It is in this context that smartphones emerge as important devices for socioaffective connections and the network of healthcare, as well as investments in health apps. Miller describes, for instance, the case of Sarah who died during fieldwork and who until the final moment of her death was active on Facebook, posting content as she wised to leave a public legacy of her life history. This most recent publication was one of the inspirations for the creation of the ASSA project (The Anthropology of Smartphones and Smart Ageing) currently in progress.

\section{REVERBERATIONS OF MILLER'S WORK IN THE SPECIAL ISSUE ARTICLES}

As highlighted earlier, this special issue presents articles by researchers who, like us, worked with Miller or gave voice to his work in Brazil. Carla Barros presents an innovative theoretical contribution with the article "Not even the sky 
is the limit: the meanings of consumption and the dynamics of social mobility in the @blogueiradebaixarenda profile on Instagram and YouTube." The researcher investigates the symbolic experiences of consumption among the popular classes, especially the relationship between consumption and social mobility. The contributions of Claudia Pereira and Fernanda Martinelli with the article "Persons, things and losses: material culture and consumption in the studies of Daniel Miller" have a special importance for this issue. Discussing mourning as a rite of passage, the authors reflect on the experiences of losing loved ones and, from another perspective, losing things/objects of symbolic value. Sandra Rúbia da Silva and Alisson Machado offer an important contribution with "Dialogues with Daniel Miller in the communication field: reflections from the research of consumption and digital cultures research group." Contrasting with the Brazilian setting, the article by Chinese researcher Xinyuan Wang considers the relevance of the concept of objectification to think about the uses of social media by young industrial workers who migrate from China's interior to its urban centres seeking to become "modern citizens."

In the Research Records section, Livia Barbosa, for example, was responsible for the first of Miller's work to be translated into Portuguese and in his account tells us something about this experience, fundamental to the development of studies of consumption in Brazil. Mylene Mizrahi, for her part, uses arguments proposed by Miller and the opportunity to work directly with the author to consider the relation between form and function in the funk aesthetic - from the "Gang trousers" to female hairstyles. Finally, Juliano Spyer describes the experience of working with Miller in the ambitious Why We Post project. 


\section{INTERVIEW WITH DANIEL MILLER}

Ana Carolina Balthazar. You were first trained in anthropology and archaeology at Cambridge University. How would you explain the experience of studying at Cambridge to a Brazilian?

Daniel Miller. Cambridge was exhilarating, but I think ultimately did me harm as well as good. As soon as I became a postgraduate student I realized I could simply turn up at seminars in any discipline. One day I would hear Anthony Giddens deliver a powerful two-hour lecture in sociology without notes, and then I would hear David Harvey in geography and next day listen to Mary Hesse in philosophy. Within anthropology itself, I went to lecture series by Edmund Leach and Jack Goody, and an early inspiration was David Clarke in archaeology. It wasn't just the calibre of people teaching. I was also fortunate that this was a period of intense intellectual discussion around three systems of ideas that transformed our consciousness: structuralism, Western Marxism and feminism. Structuralism for me was the inspiration of Lévi-Strauss and Edmund Leach, but also Barthes and Eco. It shifted us all away from thinking about things in themselves, to always seeing them in relationship to the other. My Western Marxism included Lukács, the Frankfurt School, Kolakowski and Hyppolite. It provided a basic social consciousness about poverty and oppression, but also my route to Hegel. Feminism came more though popular works such as Marilyn French's The women's room but also at the level of student discussion. It was the ideological shift that had most impact upon my private life. Overall, I see myself as immensely fortunate. This was a short period of genuine enlightenment, immensely exciting and stimulating and I don't think there has been a period quite like this since.

So, what was the harm? At that time, the culture of study was extremely competitive and aggressive. We would go to a seminar with the idea of doing everything we could to destroy the argument of the speaker and our peers. With some effect. I remember the archaeologist Lewis Binford telling me afterwards that he would make sure I never got a job anywhere, so I guess my attacks had struck home. When I subsequently become employed as a lecturer at University College London and I think for a long time thereafter I asked the most aggressive questions at seminars. It was also an elitist technique in which the only aim was to be clever. We were also taught to look down on people who did "applied" academic work that was actually changing people's lives. It took me decades to unlearn this culture, and to realise that one can be just as intellectual while also trying to be supportive and that actually being engaged in applied research was just as much a test of intellect as arguing points of philosophy. Finally, I would like to think it was the lessons of feminism that have remained, after the strict structuralism and Western Marxism have faded into anthropological history. 
A.C.B. I also remember you once told me that authors like Raymond Williams and E.P. Thompson had influenced your education, is that right? Do you see any relations between your theoretical work and the kinds of social issues they were concerned with?

D.M. These were two of many authors that expressed Marxist thinking at the time. What I took from this was probably a little different from most. If you look at my corpus of work, you can see that it has always been directed towards people who would see themselves as ordinary. I was never concerned with elites or people that were in any way special. This was certainly in the spirit of Thompson and Williams, who insisted on giving voice to those who had been ignored in history. On the other hand, they shared a tendency that was prevalent throughout that Marxist-inflected tradition to project a rather romanticised idealization of the proletariat. A counter-influence to that trend was a book by André Gorz called Farewell to the working class. I have never seen anything particularly positive about having to work in a factory, or for that matter on a farm. The only exception would be people who chose such work in preference to other livelihoods. That is one of the reasons that typically the ordinary that I aspire to lies closer to what might be called the lower middle-class, which in many countries is now also the majority of the population.

For the same reason, unlike most of my peers, I remain comfortable with what Bourdieu acknowledged is one of the primary consequences of the university system, which is helping people to become middle-class. The quiet attacks on middle-class values by university lecturers in social science, as in and of themselves suspect, has always struck me as hypocrisy. My primary role is to contribute to education, and it is based on the ideal that everyone benefits from education, and I don't have a problem if that then qualifies them as middle-class. I see on the news everyday migrants who take great risks with their own lives, often in the quest that they and their children will have these possibilities in life.

A.C.B. Were there other important references in your intellectual formation?

D.M. One key influence was Stuart Hall whom I met several times. Apart from the deep humanism of this brilliant, but also kindly man, I was very influenced by his insistence that culture is as much the project of audiences as of producers. When Hall first created what later became known as cultural studies, he promoted some wonderful ethnographic work by Hebdige, Willis and others. I have always seen it as tragic that cultural studies then abandoned deep ethnography and become more an exercise in literary exegesis. Within anthropology, key influences included Lévi-Strauss, Munn, Sahlins and Geertz. The two primary influences on my work, however, remain Bourdieu and Hegel. 
A.C.B. Now, over 30 years after launching Material culture and mass consumption, would you change anything in the book? Do you think the argument on objectification needs any kind of update?

D.M. The concept of objectification was an attempt to transcend the dualism of subject and object. There have been many similar arguments since, including by Bruno Latour, Alfred Gell and the recent discussion of ontology. But I still prefer my own concept of objectification, since I think the emphasis on process that I extrapolated from Hegel had a dynamic quality that alternatives lack. I also still employ the ideas derived from Munn about how culture comes into being. The part of that book that I would now see as outdated would be the strict differentiation between production and consumption, which in the digital world is no longer apparent. The encounter with Hegel's writing that led to that book was, alongside Bourdieu, the most important intellectual influence on my work. It was not just the Phenomenology, since I still make use of the arguments of his Philosophy of right as the basis of much of my critique of contemporary institutions. For example, I am currently writing about the way theory has become a fetish in anthropology. Theory was originally supposed to help us clarify and understand the world, but today has simply become an end in itself, as though we exploit our research about the world mainly in order to serve this deity theory. The underlying reasoning in my critique of theory in essence derives from Hegel, though blended with a touch of Wittgenstein's Philosophical investigations on the importance of ordinary language as opposed to formal theory. For me, it is about staying grounded in the messy world of contextualised ordinary activity rather than the simpler abstractions of theory. Theory is still vital but as a means to clarify and help us understand the substantive world, a means, not an end.

Monica Machado. Once you told me that The comfort of things was one of the books you most enjoyed writing. Could you tell us about your study on the lives of residents of a street in London from the point of view of household objects?

D.M. My attack on the dualism of people and things that led to a re-direction in material culture studies was not just at the level of theory. My point was that the study of objects should be a way of appreciating people. Ultimately, I am an anthropologist because I am in awe of people and one way of expressing that was a kind of democratising of the concept of the artist. In The comfort of things I saw each individual as the curator of their home interiors, taking the design of their homes as their work of art. This then grew into my sense that the sense of order that they had developed was, in effect, an expression of the aesthetic that they had developed through their life experience. This is why I cared strongly about the quality of my own writing, since I felt each chapter 
was akin to painting a portrait, which in turn respected the quality of each of my subjects as an artist.

In a book called Anthropology and the individual I theorise this movement. One starts with structuralism and the appreciation that each thing/person derives meaning mainly through their relationship to other things/meanings. We progress to the best grounding of structuralist ideas, which is the writing of Bourdieu and his documentation of how people are socialised into embodying normative culture through being brought up within that structuralist order experienced through the material culture around them. This was habitus. What I now added was the principle that this was not just true of normative culture, but also of each and every individual, who had developed their own variant of these principles in which they created their own style. The resulting idea of personal habitus is a bit like the anthropological equivalent to the colloquial concept of personality.

This issue remains important in our current project about smartphones and ageing. The problem of writing anthropology is how to respect the humanism of each and every person one has worked with and yet write at the level of generality that comes from the analysis of typicality and the normative. I am presently writing, along with my team, a book on The global smartphone. This weaves in and out between discussing general findings for fieldsites in Japan or Cameroon with trying also to give mini-portraits of individuals. In a way, though, the point has become easier, since the smartphone is unprecedented in its ability to be altered by the owner, so that a careful dissection of the smartphone shows how it quickly become highly expressive of that particular person. Through studying the smartphone one can see this process in action, a person and an object developing their joint aesthetic, which we now strive to portray as the portrait of them both. But in turn people are microcosms of the wider cultural values they have been socialised into, so the smartphone expresses typicality as well as individuality.

A.C.B. You have been a big advocate of the importance of ethnography for the production of anthropological arguments. What kinds of advice do you usually give to your students before they start doing fieldwork?

D.M. Yes, ethnography is to me the "heart" of anthropology, dedicated to human empathy, which complements the "brain" of theory. My recent projects have reinforced this view. I don't see how we can create policy, or feel educated, if we do not know what is happening in the world. My recent projects concern social media and smartphones, and much of this activity is private. Everyone in Brazil is aware that the dominant platform right now is WhatsApp. So how can we know what happens in that WhatsApp world, much of which is family conversation, intimate and private? Yet how can we talk about WhatsApp if we 
don't know that world? The only possible method is long-term ethnographic fieldwork that creates trust between the anthropologist and their participants, which means that people appreciate that no harm will come to them in sharing the everyday family communications that is the core of WhatsApp.

I give my students unusual advice. They spend months prior to fieldwork preparing an "upgrade" report about what they plan to do. I suggest to them that once that have passed their upgrade examination, they tear up this document and expect to significantly deviate from their own plans. I see fieldwork as highly opportunistic and carried out in a spirit of discovery. Once they are in the field, they will encounter things they never expected or knew about. Those could not have appeared in their upgrade, precisely because they were unknown to them at that time. Yet these are the genuine discoveries that may well be just as important to know about as those they planned to investigate. I argue that, as ethnographers, we must work as opportunists and abjure testing hypotheses which are always limited to prior knowledge.

This is not just true of individual research. My current project started with a commitment to the study of mHealth ["mobile health"] - that is, bespoke smartphone apps designed to help people with problems of health. After a few months, however, everyone in our team realised that few people were using these apps and that actually, if we wanted to consider the impact of smartphones upon health, we needed to completely rethink the very notion of mHealth - that what really mattered were the use of ubiquitous activities such as Googling, or ubiquitous apps such as WhatsApp, and not the specialist mHealth apps. We then completely changed the direction of our research away from the original grant proposal to what we now appreciated mattered more to the people we were studying.

A.C.B. Often prominent scholars give up on doing fieldwork and hire someone else to do it for them. You, instead, still do it yourself. Why?

D.M. Most of the anthropologists I learnt from had repeatedly returned to the field, such as Geertz or Barth or Leach. I see this as essential for anthropology, which at least claims to be a comparative discipline. For this sense of the comparative to be experienced by anthropologists, they need to have several dis tinctly different fieldsites that they themselves have worked in. Otherwise they tend to become overly specialist in ever more esoteric minutiae of just one particular region.

It is also hard to imagine any discipline thriving that didn't include the continual commitment to empirical experience as evidence. Every experience of fieldwork has taught me so much, and inevitably changed the direction of my thinking and my sense of what actually matters to people. Fieldwork is visceral, it becomes part of you in a way that simply reading about another 
person's fieldwork, or seeing the material from a research assistant, cannot. I admit I may be a bit extreme in that I have carried out ethnographic fieldwork on over twenty occasions. I guess it is also because I really enjoy meeting new people and hearing about their lives. I don't believe I have ever met a boring person; once you work out how to make them comfortable about expressing their views and experiences. There is always going to be something about what they do and why they do it that will be a surprise and make you realise the infinite capacity of humanity.

I also think continually going back to the field is good for one's soul. In the bubble of academia, it is easy for people to become self-important and that leads to a style of writing and speaking that can become quite abstract and hyperbolic. When you do fieldwork, people don't care at all about who you are, and mostly they see you, at least initially, as a bloody nuisance who is wanting to take up their time. This periodic experience of personal humiliation is probably a very healthy exercise, in its own right.

M.M. At what point in your career did you become interested in digital cultures as an anthropological reference? What were your motivations for conducting these studies?

D.M. I have always accepted that mainly I do not choose my research topics; rather my job is to simply acknowledge the world and direct myself to it. Often this reflects my own experience. My initial work on material culture and consumption reflected the disparity between the sheer scale of the commodity culture we lived within and the relative neglect at that period of academia. My later work on the topics of shopping and parenting reflected my own personal experiences at that time. The rise of the digital was simply inescapable; it was what we were all doing. If I decided to launch myself into it earlier than most, this probably reflects the same opportunism I have just described. I don't think I was especially prescient in recognising that digital media represented a fundamental change in the world.

I am, however, careful, in engaging with unprecedented phenomenon. I have never wanted anthropology to be the study of possible futures, or the latest digital objects. The right time for the anthropologist to pay attention comes when the device has become commonplace, such that it would already be a significant presence within an ethnography of the everyday. This can happen quite quickly. Our current project on smartphones and older people would not have been possible even two or three years ago; but in most of our fieldsites there are people in their eighties who can barely imagine doing without their smartphones. Ultimately, I am not that interested in either material objects or digital technology. My concern is with human relationships and social normativity. The legacy of the material culture studies is, however, that the best way to 
study people and society is through practice and not just language. Once people were constantly using the internet or social media, or now the smartphone, you have the opportunity to observe so much and learn so much that might not be present in interviews and conversation. If you just consider the amount of visual content that now exists online, this is an anthropological gift horse.

Take, for example, a topic I am often drawn to, that of love. People were surprised when my book A theory of shopping turned out to be a study of love. But my point was that English people are quite embarrassed and awkward talking about love. They tended to assume that just meant the romantic form. While I saw how housewives every day showed their concern for their children through their attention to detail in their shopping. I apply the same logic to digital technologies. When I go through the smartphone, app by app, I can see what it actually looks like to spend every day dealing with the dementia of one's parent. In my first book with Don Slater, The internet: an ethnographic approach, we showed how young people were quickly shifting to different ways of engagement, or how even religious practice and belief changed because of the ways in which ideas could be expressed and communicated online. You didn't have to be particularly interested in the digital itself, you just had to see its potential as a vehicle for academic research.

M.M. If I am not mistaken, the first time you mentioned the concept of polymedia was in the book Migration and new media: transnational families and polymedia, written with Madianou. Am I right? Could you explain how this academic concept has contributed to your current studies?

D.M. Yes, the concept of polymedia was created in a conversation we had about some of the conclusions of that fieldwork. It possibly helped that Madianou is Greek and that we started with a Greek term. The problem, from the beginning, was that we realised this term could be used to mean something relatively superficial, while we intended it to refer to something quite profound. The superficial interpretation was that this is just a reference to the choices people have as to which media to use. But we meant the term to refer to a re-socialising and re-moralising of media itself. Previously the choice of media had been determined by factors such as cost and access. Now with phone and internet plans, these factors faded away. As a result, people now judge each other as to which media they choose to make contact with. This turns media choice itself into an expression of morality and relationships. That is the more significant meaning of our concept of polymedia.

M.M. In the book Digital anthropology, you and Horst point out that when studying digital cultures, one should investigate the phenomena of materiality in social-cultural mediations. Could you tell us a bit more about that? 
D.M. I think that there was a huge advantage in coming to digital anthropology from the study of material culture, and again it was about seeing this trajectory at a deeper level. Of course, digital technology is itself material, and one can study where in the house people locate their computer or the implications of the size of screens - from smartphones, through tablets to laptops. But the more important legacy of material culture studies was the realisation that the key to studying digital technologies was to focus upon content, that which ordinary people created and used to populate the online world. This is the real substance of the digital and it echoes that of prior material culture studies in that it is vast.

Take one example, the rise of the visual. In my paper "Photography in the age of snapchat," I argue that social media photography is more or less the opposite of traditional photography. It used to be about keeping a record for the future, but now it is all about the present; using the smartphone to filter out and actually look at the things that matter around you. Then there is a world of new visual materials. One of the findings of our current project is the way people use emojis and stickers in places such as China and Japan. These overcome traditional formal constraints of face-to-face speech and can convey more affective feelings and emotions, so that informants tell how they wish that oral conversation could be as expressive as sticker-based conversation. This became very important for our study of care at a distance. I see all this as a continuation of material culture studies in that we dissect the substance of content and learn to sing its tunes.

M.M. In your latest book, The comfort of people, you portray a beautiful sense of humanity when investigating both online and offline experiences of people in UK hospices. Could you tell us more about it?

D.M. The work that I carried out with hospice patients was especially significant in that I think it will impact upon all my future research. I noted at the start of this interview that at Cambridge I was socialised into a rather elitist conception of academia that considered theorisation intellectual and applied work as not. I think working with the hospice made me finally realise that in many ways the abstraction represented by theory is often less challenging to the intellect, precisely because it remains at that abstract level. By contrast, applied research that has to deal with the contingency and the variety of life as lived, is actually often more challenging intellectually as well as practically. It also adds two further advantages. One is that it may actually improve people's lives, while mere critique usually just improves the status of the critic. Finally, it returns us to a core task of anthropology which is to help people appreciate the humanity of others.

It is the last of these points that is perhaps foregrounded in the storytelling style of a book such as The comfort of people. Most likely this urgency in conveying the humanity of people is linked to the subject matter. These were people 
who had been diagnosed with a terminal illness and mostly have died since the research. As I have already noted the key in anthropological writing is to blend analytical generalisation with conveying the unique character of every person we work with. These storytelling books provide one way of achieving this.

As you suggest, this book is also about blending online and offline lives. The research was intended to map the entire social universe of a person who is dying. This has to include their phone contacts and emails, but also who they see face-to-face and how often. What this has in common with my earlier study of how Filipina care workers try to parent their children half-way across the world is the necessity of online communication. People who are dying often also become less mobile as frailty becomes an issue. So, they use new technologies, not for new purposes, but simply to try and retain the social connections they might otherwise lose.

In addition, the book considers how such research might assist the hospice. I was hugely impressed by the hospice. It was the antidote to technology research. It had completely transformed the lives of these people. But not at all because of any new technology. It was simply by reconceptualising from the negative sense of the final stage before death into a positive last opportunity to do interesting and worthwhile things with one's life while one still had it.

Communication is particularly important since people want to stay in their homes for as long as possible, so mostly the hospice staff are dealing with patients in their homes, not in the hospice. This was the opportunity to actually employ ideas that had started as theories. For example, polymedia became a specific recommendation to hospice staff, suggesting that they start by as certaining how each patient preferred to use media in communicating with them. Might they prefer a text first to alert them that they were about to get a phone call, or to prepare themselves for a webcam discussion? It was a revelation to doctors that patients may not always prefer face-to-face when hearing news about the development in their cancer.

Another significant finding was that the factor that proved most harmful to patients, other than their disease, was the medical profession's obsession with confidentiality. As a result, medical information was not being passed between the many different groups that look after them. I find it immensely frustrating that when we talk about our smartphone research, audiences constantly emphasise privacy and confidentiality over almost any other factor. They simply cannot imagine that, as well as being sometimes something we would all want to protect, privacy and confidentiality can also become a significant cause of harm to ordinary people.

M.M. In all your recent studies the perspective of comparative anthropology is an important piece to identify the different uses of social technologies in different places. What are the main differences between digital sociabilities in Brazil and England? 
D.M. The first point is simply that Brazil is not comparable to England because the former is far more heterogeneous than the latter. There are differences in England between north and south, across gender and inequalities in income, but Brazil is more like a continent than a country. For example, I was watching the film by Flavia Kramer on the impact of new media for the Bororo people studied by Lévi-Strauss - a fascinating intersection between anthropological interest in issues such as moieties and marriage rules, alongside the rise of social media and smartphones. Clearly, however, lessons from Amazonia do not apply to professionals in São Paulo. Currently Marilia Duque is working, as part of our team, on ageing with smartphones in São Paulo. She finds, for example, that retired people focus on retaining their links to their previous working lives, which remains central to their sense of identity. By contrast, in my most recent ethnography in Ireland (clearly NOT England, but not far). I found that working with retired people, even after a year, you might not know what job they had prior to retirement.

The best evidence we have, however is the published book by Spyer on Social media in emergent Brazil. Again, you can't really say this is "Brazil," since the people in this Bahian squatter community are entirely different from the professionals being studied by Duque. But what is clear is that there are many aspects of sociality that bear no relation to the English, including all sorts of regimes of secrecy, but also gossip, that his book expertly dissects. By contrast, my own book Social media in an English village, explains a very specific form of English sociality based on what I call the "Goldilocks" principle, where the main use of social media is to create a new degree of sociality in which people are seen as sufficiently connected that they are not ignoring relatives and friends. But this is used to legitimate keeping these people at a distance, so one doesn't actually need to talk to them or see them. This antipathy to sociality is very English and contrasts with the much more expansive and frankly friendly sociality that English people almost always remark upon when they gain some experience of Brazil.

M.M. In several of your recent studies, digital environments appear as spaces of cultural contradictions, offering not only opportunities for social expansion, a sense of co-presence, mediating long distance affection, but also restrictions of world views, such as lack of freedom, social control, the spreading of hate speech and intolerance. How do you see the future of digital platforms and democratic cultures in the world?

D.M. My first response is one of caution. I see the impact of new media on politics as an arena of fake news, but I mean something quite different from that phrase. It is the hype around fake news that may be the main fake news. Similarly, for years we have been told that new media creates a "filter bubble" 
which narrows the exposure of people to the media, but as far as I am aware the evidence has always been that the opposite is true. Works such as Axel Bruns's Are filter bubbles real? or David Sumpter's Outnumbered tend to be ignored so almost everyone thinks that social media creates "filter bubbles" even when they don't. In my first book about the internet, with Don Slater, we pointed out that the reason there is so much hate speech online is that this tends to be stuff that wasn't taken seriously, and no one would publish anywhere else. The fact that it all ends up online was a sign of its insignificance, rather than significance. The term fake news has the absurd consequence of deluding people into thinking that news prior to social media was mainly true. Here in England the lies that led to Brexit came almost entirely from established tabloid newspapers, far more than from social media

The problem is that the newspapers whose financial interest are being undermined by new media tend to be relentless in their critique. Since I am usually trying to oppose that with evidence, my work sounds like it is biased towards the positive consequences of new media. This is not the case. I am just trying to keep us wedded to evidence. In my current work, for example, I am examining how Googling for health information exacerbates class differences when it appears to be merely neutral. This is a negative most people are unaware of. If we were to take a broad brush and look at the evidence overall, I think I would say that new media's effects are, not surprisingly, equally positive and negative on the field of democratic politics as in most other things. Social media can potentially help develop an Arab Spring, but equally populist politics such as the Italian Five Star movement in Italy, that takes much of its ideology from the democratic possibilities of the internet, suffers from the contradictions of most populist parties. But then I have always argued that people who try and see impacts as good or bad are generally being simplistic. I am a follower of the work of the sociologist Georg Simmel who presents clear theoretical grounds for expecting new cultural developments to be inherently contradictory.

Having said all that, there are clearly dangers that digital technologies allow a degree of surveillance and control that could make authoritarian regimes extremely effective. Recently one of my team, Xinyuan Wang, wrote a piece (in The Conversation) that explained why people in China may be less opposed to the social credit system than outsiders to China imagine. Nevertheless, these systems should certainly make us fearful of the potential for a form of absolute political control that is unprecedented.

A.C.B. Do you consider your work to be political in any way? How exactly?

D.M. I was educated in the work of Habermas, who clearly showed that all academic work is political. But I have strong views on where that politics should be best directed. There is much good work within the field of cultural studies, 
but I would suggest that precisely because it tends to foster work that favours the author's political stance, it loses credibility. If someone from gender studies argued that gender is highly significant for some study, it could be read as simply a reflection of their institutional role. Perhaps influenced by Karl Popper, I have always tried to come up with evidence that does not necessarily support my own politics. For example, I found that supermarkets might have ethical consequences that were superior to corner shops, even though I personally want to favour corner shops. You should not know my politics from my findings. Research itself should be as objective as possible so that people trust that it is a direct reflection of evidence not the author's institutional position.

The politics comes subsequently, when we consider how our research should engage with policy. Indeed, the key point is that it should engage. I have seen generations of academics, whose only stance is pure critique, claiming that they are more political than I am. But their work has rarely resulted in changes to policy. By contrast, I am now increasingly involved in trying to engage our research in actually improving people's welfare. The most powerful critique is the demonstration that something could be feasibly done better than the status quo. So, in our current work, we are distinct from the vast commercial industry that promotes and develops mHealth Apps and instead publishing documents that show some of this could be done for free using ubiquitous free apps such as WhatsApp. Marilia Duque has created an impressive manual on how WhatsApp could be used for health in Brazil. I believe my work is political to the degree that I can actually see people's welfare has been improved as a direct result of our work. Pure critique to me is often self-indulgence and therefore ultimately conservative.

A.C.B. Your work often draws on some of Pierre Bourdieu's arguments. He has made important claims regarding the role of academia in the reproduction of social hierarchies. Is it possible to develop work in academia that does not contribute to social distinction? How exactly?

D.M. I have already mentioned that in some ways Bourdieu could be argued as saying something else. While academia has in the past mainly reproduced social hierarchies, the effect of the university system is to create and sustain the middle-class - that is, people who view the world through a sophisticated lens of distinction informed by education, while Bourdieu portrays the working class as generally having a more immediate or literal interpretation of what they encounter, which he may also see as more authentic. I have always believed that education is vastly superior to ignorance. The problem for me is that the universities only serve a minority, and we want everyone to have access to these educational possibilities.

This is something I am also trying to put into practice. Before the arrival of digital technologies, I could only speak to 30 or sometimes 300 in a 
lecture theatre. But in our last Why We Post project, our free online university course was taken by over 30,000. I am especially excited that our books, most of which are ethnographic monographs, have been downloaded by more than 875,000 . Especially important are the numbers we see in countries with emerging middle classes and subsequent demand to expand tertiary education such as Ethiopia or the Philippines.

How have we achieved this? The first factor is that all our research dissemination consists of free "Open Access" books, or a free online university course. Perhaps even more importantly we only use colloquial English, that is words which someone finishing high school would understand. I believe most theory can be explained in ordinary language, and the reason people don't is often because the theory is weak and is being artificially protected by obfuscation. Our style of writing is intended to be highly accessible, mostly told in the form of stories about recognisable people. We also translate our work into the languages of the places where we work, such as Hindi and Tamil. In addition, we use new media to publicise our work through social media platforms, blogs and by providing simple versions of our arguments on websites that get people interested in reading the more complex work. This does not dilute our academic output. That project produced I I books - more than 2,000 pages of evidence. I really don't mind if, to some degree, this giving away of education for free is destructive of the traditional university system as we have known it. In its current form it is elitist, as Bourdieu indicated. In our work we are trying to push towards what I see as sophisticated original insights, which is the value of research, but made available to everyone, especially those who don't have the money to go to universities, but may be extremely interested in knowing more about the consequences of social media or smartphones. Education is a human right and to the degree that this is possible, it should be free.

A.C.B. What do you feel you achieved through the Why We Post project and how does your current project aim to go beyond that?

D.M. The single most important achievement of Why We Post is the evidence that it collected about the uses and consequences of social media and the fact that this was ethnographic evidence. The point is that most arguments about social media come from disciplines that skim off only the publicly available evidence. There is a vast amount of work about the political consequences of Twitter, since academics have easy access to Twitter. Some also tend to universalise their findings. But our work should incorporate everything that people do and the diversity between different populations. As I noted above, this must include the private worlds found on platforms such as WhatsApp that are more consequential for ordinary people. So that project was committed to providing scholarly evidence which is made readily available through mass dissemination. 
Today it seems natural to progress to smartphone-based research. Social media itself is no longer a separate entity, but rather a set of apps alongside other smartphone apps. The smartphone itself is unprecedented in its intimacy and power as a personal device. So, the first stage has been to replicate what was successful about Why We Post. This time we have I I team members involved in I6-month ethnographies and we hope again to produce I I books. ${ }^{2}$

The topic has been expanded by the focus upon ageing as the context. Most studies of ageing focus on people defined by age - that is youth and the elderly. Yet the primary change in ageing has been for people who see themselves as neither elderly nor young. This varies across our different sites. In Ireland, for example, people in the sixties, seventies, and even eighties, who expected by now to be elderly, find that that they are still listening to the Rolling Stones, while smoking dope like the hippies they once were. They are doing many of the same things they have always done, perhaps still dating. This is not what being elderly was expected to feel like. The recent introduction of the smartphone to their lives is, then, an iconic moment in this retained sense of youth. In many ways I suspect it will be our findings about the transformation of ageing that will outlast our work on smartphones.

In addition, this project has an orientation towards applied anthropology that didn't exist in Why We Post. It is represented by the challenge to conventional mHealth that I have just referred to. Each team member has their own project relevant to their own fieldsite and only selected after they had finished nearly a year's fieldwork. This ensured that it arose from their sense of what was needed, not simply what they would have liked to do. This represents a set of new challenges that I find a welcome addition to the ambitions of Why We Post.

Finally, I want to see this project as a demonstration of my ambitions around changing the role of theory in anthropology. How can we have theory that is not a form of fetishism? The answer I believe is to return theory to its initial role as the handmaiden to understanding and explaining our substantive findings. In writing The global smartphone there are many theoretical interventions that generalise our comparative study of the use and consequences of smartphones. This includes our definition of the smartphone as The Transportal Home: more a place within which we live, than a device we just use. We argue that the smartphone goes Beyond Anthropomorphism. Theories of the robot are relatively superficial in that the robot is supposed to look like a human being. By comparison, the smartphone's relationship to humanity is more intimate, reciprocal and profound. We discuss the phenomenon of "perpetual opportunism", and the role of the smartphone as a Control Hub and Care Transcending Distance. We have new ways of conceptualising what we call social ecology and screen ecology. The book is replete with what might be called theory, and we are in no way anti-theoretical. It is just that in every case theory is clearly illus- 
trated by ethnographic evidence that shows how it means different things for each population. It doesn't look like theory because we spend so much effort trying to make the arguments clear and accessible. We examine the way it clarifies our original insights to a greater extent than how it contributes to established theoretical debates. The book thereby exemplifies what I hope de-fetishised theory within anthropology might look like in the future.

A.C.B. What is the next project?

D.M. This will be my longest answer since I am someone who has always been much more orientated to the present and future and not especially interested in the past. There are three phases to this, but they shift from projects that are pretty definite, to ideas that at the moment are more like dreams that may or may not become reality.

At present, I am just half-way through our five-year project, and I am hugely enthusiastic about the results. When we started the idea of linking three topics - the transformation of middle-age, the question of what a smartphone is, and whether we could contribute to mHealth - this seemed a bizarre beast, part giraffe, part crocodile, part spider. Yet at this point we simply can't imagine how you could tackle any one of these three topics except in combination with the others. Finding that ubiquitous apps, such as WhatsApp, were more important than bespoke apps, is linked to understanding both what a smartphone is and how ageing has changed. Presently we are completing The global smartphone and then we hope there will be nine monographs all with the titles of Ageing with smartphones in each of our various fieldsites. We intend to write an edited book about our alternatives to mHealth, but also will publish comparative work on ageing, probably in journal papers.

If, however, you spend I 6 months living in a fieldsite as an ethnographer, you end up with far more material than that dictated by your project. I find I want to write a book that has little to do with this project and is more what struck me from the ethnographic experience. The title I would like to give this book has been ruined by Monty Python, since you can't use the expression “The meaning of life" without thinking of them. Yet actually this would be the topic of my book. I worked with retired people who had undergone a profound shift from Catholicism to secularism, from poverty to affluence and from many constraints to a form of freedom that is, perhaps, unprecedented in human history. I suspect there are many parallels to this amongst populations in Brazil. I spent some of my time asking people about life purpose. As you might expect, they had very little to say in response and found the topic vaguely embarrassing. This was also true of my previous work with hospice patients who were dying. So instead, I think we need to extrapolate issues about life purpose from what people do, rather than what they say. 
I won't even start writing this book for another year or so, but in my head, there is a fantasy that much of the book will come from the ethnographic findings. But once that is written, I will then compare it to classic philosophy and discussions of life purpose in ancient Greece and Rome. There is a little of this in the book Aging thoughtfully by Martha Nussbaum and Saul Levmore. I would want to go much further, with more extensive discussion of various movement such as the Stoics, Epicureans and others. My argument would be that later philosophy is mainly influenced by religion, while these earlier classical sources are in some ways closer to the largely secular world of my contemporary Irish retirees. I also imagine writing about issues such as the nature of community and consumption as seen from the same perspective.

Even more in the realms of fantasy would be a project that would start only when my present five-year project is complete, that is three years from now. Unfortunately, with the UK leaving the EU - something that I see as a complete disaster in so many ways - I may be no longer eligible for the scale of funding I will have enjoyed for the last ten years. Yet I feel that these largescale comparative projects offer something to comparative anthropology that is more than just the aggregate of smaller projects. So, I would love to have the opportunity to conduct another such programme in the future; if I can find the funding to do so, which is doubtful. As for the topic, this is even more tentative, but I am currently thinking about what seems to be something of a crisis in young people's relationships; issues around commitment and intimacy. This would follow from previous work I have carried out on the nature of love. I don't think I would carry out such an ethnography myself - I am too old. At this point I would rather concentrate on helping young people train as ethnographers and gain their own expertise.

More than once in my career I have wondered about whether to send my research upwards to the discussion of political economy, or downwards to issues of intimacy. Much of my work has been about capitalism, theories of value, the rise of audit culture, climate change and similar topics. But mostly I tend towards the study of relationships. Partly personal preference. I am very happy sitting in a pub listening to people talking at length about their relationship problems and giving them my often terrible advice as to how to solve these. But more than that, there is an academic alignment. As we see in the digital media research, so much of what matters to people happens in private worlds. If ethnographers are the only researchers who could ever really know what is going on there, since access to such information completely depends upon trust, perhaps we have a particular responsibility to engage in those studies. No other methodology has the time patience, or possibly the desire, to spend so much effort on building trust. Yet this is the key part of people's lives, that which usually determines whether they feel life is happy and worthwhile or otherwise. 
I have no idea if I will have the funding, good health or opportunity to embark on these future journeys. Quite possibly I will come up with completely different ambitions over the next few years. As I have noted throughout these answers, I am best characterised as an optimistic opportunist; I don't know the future, but I feel something interesting will turn up. Alongside many academics, once my work appears in print, I only see the faults and I am ashamed and feel the result is immature; but I am also convinced that my next project will actually achieve some maturity and might even suggest I am finally growing up (though I know, and all my friends know, that will never happen).

Received on 3/ May/2020 | Approved on I9/Oct/2020

Ana Carolina Balthazar holds a PhD in Social Anthropology from University College London (UCL) and is currently pursuing a postdoc (PNPD/CAPES) at PUC-Rio. She researches material culture and nationalism in the United Kingdom and Brazil and has published articles in international academic journals like American Ethnologist and the Journal of Material Culture.

Monica Machado is Associate Professor of the School of Communication at the Federal University of Rio de Janeiro and Professor of the Eicos- IP/UFRJ Postgraduate Program. She leads the MEDIATIO research group. She gained her PhD in Communication and Culture on the PPGCOM program at ECO-UFRJ. She was Honorary Research Associate (20I4-20I5) at University College London (UCL) in the United Kingdom under the supervision of Daniel Miller and funded by a Capes award. Her most recent book is Antropologia Digital e Experiências Virtuais do Museu de Favela. Her current line of research is the media and sociocultural mediations with an emphasis on communication, material culture, digital anthropology, and communities. 


\section{NOTES}

I Both projects are on the site of UCL Anthropology (UK): <https://www.ucl.ac.uk/why-we-post/ and https://blogs. ucl.ac.uk/assa/about/>. Accessed 28 September 2020.

2 Here Miller refers to his current project, funded by the European Research Council, The Anthropology of Smartphones and Smart Ageing (ASSA): see https://blogs.ucl. ac.uk/assa/.

\section{BIBLIOGRAPHY}

Adorno, Theodor \& Horkheimer, Max. (I944). The culture industry: selected essays on mass culture. London: Routledge. Balthazar, Ana Carolina. (202I). Ethics and nationalist populism at the British seaside. London: Routledge (in press). Bourdieu, Pierre. (1977). Outline of a theory of practice. Cambridge: Cambridge University Press.

Douglas, Mary \& Isherwood, Baron. (I979). The world of goods. New York: Basic Books.

Goffman, Erving. (1975). Frame analysis: an essay on the organization of experience. Cambridge, US: Harvard University Press.

Gombrich, Ernst. (I979). The sense of order: a study in the psychology of decorative art. Oxford: Phaidon.

Hebdige, Dick. (I98I). Object as image: the Italian Scooter Cycle. Block 5, p. 44-64.

Hegel, Georg Wilhelm. (I977) [I807]. Phenomenology of spirit. Oxford: Clarendon Press.

Horst, Heather \& Miller, Daniel (eds.). (20I2). Digital anthropology. London: Bloomsbury.

Klein, Melanie. (I975). Notes on some schizoid mechanisms. In: Envy and gratitude. London: The Hogarth Press. Laidlaw, James. (2013). The subject of virtue: an anthropology of ethics and freedom. Cambridge: Cambridge University Press.

Livingstone, Sonia. (2002). Young people and new media. Childhood and the changing media environment. London: Sage Publication. 
Machado, Monica. (2017). Antropologia digital e experiências virtuais do Museu de Favela. Curitiba: Appris.

Madianou, Mirca \& Miller, Daniel. (2012). Migration and new media: transnational families and polymedia. London: Routledge.

Marx, Karl. (1975). Early writings. Harmondsworth Mx: Penguin.

Mattingly, Cheryl \& Throop, Jason. (2018). The anthropology of ethics and morality. Annual Review of Anthropology, 47, p. 475-492.

Miller, Daniel. (2017a). Anthropology is the discipline but the goal is ethnography. HAU: Journal of Ethnographic Theory, 7/I, p. 27-3I.

Miller, Daniel. (20I7b). The comfort of people. Cambridge: Polity Press.

Miller, Daniel. (2013). Trecos, troços e coisas. Rio de Janeiro: Zahar.

Miller, Daniel. (2010). Stuff. London: Polity Press.

Miller, Daniel. (2008). The comfort of things. Cambridge: Polity Press.

Miller, Daniel. (2005). Materiality: an introduction. In: Materiality. Durham/London: Duke University Press.

Miller, Daniel. (2002). Teoria das compras: o que orienta as escolhas dos consumidores. São Paulo: Nobel.

Miller, Daniel. (1995a). Acknowledging consumption: a review of new studies. London: Routledge.

Miller, Daniel. (I995b). Consumption as the vanguard of history: a polemic by way of an introduction. In: Acknowledging consumption: a review of new studies. London: Routledge, p. I-52.

Miller, Daniel. (1987). Material culture and mass consumption. Oxford: Blackwell.

Miller, Daniel \& Sinanan, Jo. (2014). Webcam. Cambridge: Polity Press.

Miller, Daniel \& Slater, Don. (2000). The internet: an ethnographic approach. Oxford: Berg.

Piaget, Jean. (1962). Plays, dreams and imitations in childhood. London: Routledge and Kegan Paul. 
MATERIAL CULTURE AND MASS CONSUMPTION: THE IMPACT OF DANIEL MILLER'S WORK IN BRAZIL

802

Simmel, Georg. (1978) [1907]. The philosophy of money. London/Boston: Routledge and Keegan Paul.

Spyer, Juliano. (2017). Mídias sociais no Brasil emergente:

como a internet afeta a mobilidade social. London: UCL Press. 
Palavras-chave

Cultura material; consumo; mídia digital.
Keywords

Material culture; consumption; digital media.
MATERIAL CULTURE AND MASS CONSUMPTION: CONSIDERAÇÕES SOBRE O IMPACTO DA OBRA DE DANIEL MILLER NO BRASIL

\section{Resumo}

Este artigo introduz o número especial sobre o impacto do livro Material culture and mass consumption, de Daniel Miller, para o debate interdisciplinar das ciências sociais no Brasil. Nesta Apresentação, nós, as organizadoras, fazemos uma revisão das principais ideias contidas no livro - que nunca foi traduzido para o português -, além de considerar algumas críticas que surgiram nas últimas décadas sobre a obra. Abordamos também a relação da teoria do consumo de Miller e sua larga produção em antropologia digital. Em seguida, numa entrevista com o próprio Miller, discutimos algumas das impressões que temos sobre sua perspectiva teórica e trajetória profissional. Por fim, o texto apresenta os quatro artigos originais que, a partir de dados de pesquisa empírica, discutem a pertinência daquele estudo inicial sobre consumo e cultura material para o atual debate teórico sobre materialidades, mídias sociais e trocas interdisciplinares. Além disso, o artigo também introduz a seção Registros de Pesquisa, em que pesquisadores próximos a Miller escrevem sobre a sua produção teórica, colaborações acadêmicas e parceria profissional.

\section{MATERIAL CULTURE AND MASS CONSUMPTION:} THE IMPACT OF DANIEL MILLER'S WORK IN BRAZIL

\section{Abstract}

This article introduces the special issue reflecting on the influence of the book Material culture and mass consumption by Daniel Miller on interdisciplinary debates in social science in Brazil. Here we review the main arguments presented in the book - yet to be translated into Portuguese - while also considering some of the criticism it has received in past decades. Next, we present the connection between Miller's theory of consumption and his wideranging work in digital anthropology. Afterwards, we introduce the four original papers contained in this special issue and which consider, based on empirical research, the on-going relevance of Miller's theory to current debates on materiality, social media and interdisciplinary exchange, including an interview with the author. Finally, in this introduction, we also present the section Registros de Pesquisa, where different Brazilian researchers discuss the opportunity of working closely with Miller. 